\title{
Biosynthesized silver and gold nanoparticles are potent antimycotics against opportunistic pathogenic yeasts and dermatophytes
}

This article was published in the following Dove Press journal:

International Journal of Nanomedicine

\author{
Andrea Rónavári ${ }^{1,2}$ \\ Nóra Igaz ${ }^{2}$ \\ Mohana Krishna Gopisetty ${ }^{2}$ \\ Bettina Szerencsés ${ }^{3}$ \\ Dávid Kovács ${ }^{2}$ \\ Csaba Papp ${ }^{3}$ \\ Csaba Vágvölgyi ${ }^{3}$ \\ Imre Miklós Boros 2,4 \\ Zoltán Kónya ${ }^{1,5}$ \\ Mónika Kiricsi² \\ Ilona Pfeiffer ${ }^{3}$ \\ 'Department of Applied and \\ Environmental Chemistry, \\ ${ }^{2}$ Department of Biochemistry and \\ Molecular Biology, ${ }^{3}$ Department of \\ Microbiology, Faculty of Science and \\ Informatics, University of Szeged, \\ Szeged, ${ }^{4}$ Institute of Biochemistry, \\ Biological Research Centre of the \\ Hungarian Academy of Sciences, \\ 5MTA-SZTE Reaction Kinetics and \\ Surface Chemistry Research Group, \\ Szeged, Hungary
}

Correspondence: Ilona Pfeiffer Department of Microbiology, Faculty of Science and Informatics, University of Szeged, Közép fasor, 52 H-6726,

Szeged, Hungary

Tel +36 62544517

Fax +36 62544823

Email pfeiffer@bio.u-szeged.hu

Mónika Kiricsi

Department of Biochemistry and

Molecular Biology, Faculty of Science and Informatics, University of Szeged, Közép

fasor, $52 \mathrm{H}-6726$, Szeged, Hungary

Tel/fax +36 62544887

Email kiricsim@bio.u-szeged.hu
Background: Epidemiologic observations indicate that the number of systemic fungal infections has increased significantly during the past decades, however in human mycosis, mainly cutaneous infections predominate, generating major public health concerns and providing much of the impetus for current attempts to develop novel and efficient agents against cutaneous mycosis causing species. Innovative, environmentally benign and economic nanotechnologybased approaches have recently emerged utilizing principally biological sources to produce nano-sized structures with unique antimicrobial properties. In line with this, our aim was to generate silver nanoparticles (AgNPs) and gold nanoparticles (AuNPs) by biological synthesis and to study the effect of the obtained nanoparticles on cutaneous mycosis causing fungi and on human keratinocytes.

Methods: Cell-free extract of the red yeast Phaffia rhodozyma proved to be suitable for nanoparticle preparation and the generated AgNPs and AuNPs were characterized by transmission electron microscopy, dynamic light scattering and X-ray powder diffraction.

Results: Antifungal studies demonstrated that the biosynthesized silver particles were able to inhibit the growth of several opportunistic Candida or Cryptococcus species and were highly potent against filamentous Microsporum and Trichophyton dermatophytes. Among the tested species only Cryptococcus neoformans was susceptible to both AgNPs and AuNPs. Neither AgNPs nor AuNPs exerted toxicity on human keratinocytes.

Conclusion: Our results emphasize the therapeutic potential of such biosynthesized nanoparticles, since their biocompatibility to skin cells and their outstanding antifungal performance can be exploited for topical treatment and prophylaxis of superficial cutaneous mycosis.

Keywords: antifungal activity, biological synthesis, dermatophytes, opportunistic pathogenic yeasts, silver nanoparticles, toxicity

\section{Introduction}

Due to social and global environmental changes, the aging population and the growing number of susceptible individuals (eg, patients with predisposing factors), the incidence of superficial mycosis has increased over the past few years causing health problems world-wide. ${ }^{1,2}$ Dermatomycosis usually manifests as itchy, sore skin rashes and tinea on the toes, the inner thighs or groin; leading to flaking and blistering of the affected area. Fungi may spread to the scalp or nails causing hair loss and thickened or deformed fingernails. The etiological agents behind dermatomycosis are mostly filamentous dermatophytes (eg, Microsporum spp., Trichophyton spp. or Epidermophyton spp.), however, several opportunistic yeast species such as Candida or Cryptococcus can invade keratinized tissues. ${ }^{1,3}$ In case of cutaneous candidiasis, the origin is mostly 
endogenous as the causative agents (ie, Candida spp.) are the resident or transient members of the human dermal microflora. Cryptococcus neoformans can induce meningitis in immunocompromised patients, however, due to systemic dissemination of yeast cells in such patients, skin lesions may also appear. ${ }^{4}$ In addition to this secondary variant, a primary form of cutaneous cryptococcosis has recently been identified, where the pathogen enters the body directly through skin injury. ${ }^{5}$ Regardless of the distinct origins of $\mathrm{Cr}$. neoformans infections, this pathogen can cause life-threatening systemic complications in the host. ${ }^{4,5}$ Therefore, there is an inevitable and urgent medical need to find novel and efficient agents to defeat opportunistic pathogens and cutaneous mycosiscausing species. To achieve this goal, an innovative, environmentally benign and economic approach is required.

A solution that fulfills these demands could be based on nanotechnology, since owing to the abundance of recent scientific advancements in this field, it is now possible to design and develop nano-sized structures with unique properties tailored for specific applications (eg, in optics, in electronics, in catalysis, and in household items, as well as in medicine). ${ }^{6}$ In recent years, gold nanoparticles (AuNPs) and silver nanoparticles (AgNPs), ${ }^{7}$ in particular, have been in the focus of increasing interest due to their simple synthesis and desirable biological activities (ie, antitumor, antibacterial, antiviral and antifungal effects). ${ }^{8} 9$ We have reported that the cytotoxic features of AgNPs can be exploited to kill p53 tumor suppressor-deficient ${ }^{10}$ as well as multidrug-resistant cancer cells, ${ }^{11}$ providing some further details to the mechanism of AgNP-induced antitumor actions. In recent years, several studies have also demonstrated that AgNPs, synthesized either by conventional chemical reduction methods, physical techniques or by different biological entities, exhibit potent inhibitory effects against Gram positive and Gram negative bacterial species and induce cytotoxicity in various pathogenic fungi. ${ }^{8,12}$ Green alternatives to harsh reducing chemicals and environmentally benign capping agents have also been developed to reduce the costs of nanoparticle production and to minimize the generation of hazardous wastes upon the synthetic procedures. ${ }^{13}$ In a comprehensive study on AgNPs obtained by chemical reduction using coffee and green tea extracts, we proved the remarkable antimicrobial efficiency of such particles, ${ }^{14}$ and we showed evidence that the green material used for AgNP synthesis can largely define the physical, chemical and biological characteristics of the produced nanomaterial. ${ }^{14}$

Owing to widespread applications, there is an ever-growing demand for AgNPs and AuNPs, while the challenges of their economical, environmentally safe and sustainable production should also be addressed. A rapidly progressing area of nanobiotechnology is the microbe-assisted nanoparticle synthesis, ${ }^{15}$ where bacterial strains, yeast- and alga-mediated reactions are exploited for nanoparticle generation. ${ }^{16,17}$ One such study demonstrated that the astaxanthin-containing green alga Chlorella vulgaris is a useful agent for gold nanoparticle synthesis. ${ }^{18}$ Based on this observation we hypothesized that Phaffia rhodozyma (perfect state Xanthophyllomyces dendrorhous), a basidiomycetous red yeast with high astaxanthin content, ${ }^{19}$ might also be a potential candidate for microbe-assisted nanoparticle synthesis. Therefore, the aim of this present study was to investigate the suitability of $P$. rhodozyma cell-free extract for the preparation of AgNPs and AuNPs. Since our synthesis method proved to be successful, the as-prepared nanoparticles were characterized, and a complex biological screening was carried out to determine their biological activity, where beside toxicity to human skin-derived cells, the antifungal efficiency of the bio-synthesized nanoparticles was also assessed with a special emphasis on inhibitory features against opportunistic pathogenic yeasts and dermatophytes.

\section{Materials and methods Preparation of $P$. rhodozyma cell-free extract}

P. rhodozyma American Type Culture Collection (ATCC) 24203 cells grown on $2 \times$ yeast extract peptone dextrose (YPD; Sigma-Aldrich Co., St Louis, MO, USA) (2\% D-glucose, $2 \%$ peptone, $1 \%$ yeast extract and $2 \%$ agar) plates at $22^{\circ} \mathrm{C}$ for 5 days were collected by cell scraper. Ten grams of wet weight biomass were suspended in $200 \mathrm{~mL}$ sterile distilled water and the cells were disrupted in Bead Beater (BioSpec Products, Inc., Bartlesville, OK, USA) using glass beads with $0.5-1 \mathrm{~mm}$ diameter. Cell debris was removed by centrifugation at $18,000 \mathrm{~g}$ for $15 \mathrm{~min}$ in Sorvall RC-5B centrifuge (Thermo Fisher Scientific, Waltham, MA, USA) at $4^{\circ} \mathrm{C}$. The supernatant was filtered through $0.45 \mu \mathrm{m}$ pore sized nitrocellulose membrane (Merck KGaA, Darmstadt, Germany). The filtrate was used as a reducing agent and stabilizer for the synthesis of nanoparticles.

\section{Synthesis of AgNPs and AuNPs}

After optimization of the nanoparticle synthesis process, the following protocol was used. For preparation of AgNP, $90 \mathrm{~mL}$ cell-free extract ( $\mathrm{pH}$ 6.7) was mixed with $10 \mathrm{~mL}$ of $1 \mathrm{M} \mathrm{AgNO}_{3}$ suspension. Gold nanoparticles were synthesized similarly, by adding $10 \mathrm{~mL} 1 \mathrm{M} \mathrm{HAuCl}_{4}$ solution to $90 \mathrm{~mL}$ cell-free extract. Both suspensions were constantly stirred using an orbital shaker at $22^{\circ} \mathrm{C}$ for 24 hours. Nanoparticles were pelleted by centrifugation for $15 \mathrm{~min}$ at $18,000 \mathrm{~g}$ in 
Sorvall RC-5B centrifuge at $4^{\circ} \mathrm{C}$ then washed twice with sterile distilled water. The final colloid suspensions were characterized and stored at $4^{\circ} \mathrm{C}$.

\section{Characterization of nanoparticles}

The morphological features of the synthesized AgNPs and AuNPs were analyzed by transmission electron microscopy (TEM) using a FEI Tecnai $\mathrm{G}^{2} 20$ microscope (FEI Corporate Headquarters, Hillsboro, OR, USA) at an acceleration voltage of $200 \mathrm{kV}$. The hydrodynamic particle size distribution of the samples was assessed by dynamic light scattering (DLS) analysis using a Zetasizer Nano Instrument (Malvern Instruments, Malvern, UK). The crystal structures were examined by X-ray powder diffraction (XRD), where the scans were performed with a Rigaku MiniFlex II powder diffractometer (Rigaku Corporation, Tokyo, Japan) using $\mathrm{Cu} \mathrm{K} \alpha$ radiation. A scanning rate of $2^{\circ} \mathrm{min}^{-1}$ in the $20^{\circ}-80^{\circ} 2 \theta$ range was used. Finally, the optical properties of the obtained AuNPs and AgNPs were studied using an Ocean Optics 355 DH-2000-BAL ultraviolet-visible (UV-VIS) spectrophotometer (Halma PLC, Largo, FL, USA) in a $10-\mathrm{mm}$ path length quartz cuvette. The absorbance spectra of nanoparticles were recorded within the range of $300-800 \mathrm{~nm}$.

\section{Cell culture}

$\mathrm{HaCaT}$ immortalized keratinocyte cell line from adult human skin was purchased from ATCC. HaCaT cells were maintained in Dulbecco's Modified Eagle's Medium (DMEM) containing $4.5 \mathrm{~g} / \mathrm{L}$ glucose, supplemented with $10 \%$ fetal bovine serum, $2 \mathrm{mM}$ L-glutamine, $0.01 \%$ streptomycin and $0.005 \%$ ampicillin. Cells were cultured under standard conditions in a $37^{\circ} \mathrm{C}$ incubator at $5 \% \mathrm{CO}_{2}$ in $95 \%$ humidity.

\section{Cell viability and toxicity assays}

MTT mitochondrial activity assay (Sigma-Aldrich) was performed to measure cell viability. HaCaT cells were seeded into 96 well plates (10,000/wells) and treated with either AgNPs or AuNPs, or with cisplatin in different concentrations on the following day. After 24-hour treatments cells were washed with phosphate buffered saline (PBS) and incubated with culture medium containing $0.5 \mathrm{mg} / \mathrm{mL}$ MTT reagent for 1 hour at $37^{\circ} \mathrm{C}$. Formazan crystals were solubilized in DMSO and extinction was measured at $570 \mathrm{~nm}$ using a Synergy HTX plate reader (Thermo Fisher Scientific). Absorption corresponding to the untreated control samples was considered as $100 \%$. MTT assays were performed at least three times using four independent biological replicates.

Cytotoxicity of the synthesized nanoparticles was assessed by crystal violet staining as well. For this, HaCaT cells were seeded into 24 well plates and were left to grow until they reached confluence. Then cell layers were treated with nanoparticles or with cisplatin for 24 hours. After each treatment, cells were washed three times with PBS and fixed using methanol:acetone 70:30 mixture. Fixed cells were then stained using $0.5 \%$ crystal violet dissolved in $25 \%$ methanol, washed with distilled water then air-dried. Plates were photographed, and crystal violet was solubilized using $400 \mu \mathrm{L} \mathrm{10 \%}$ acetic acid. From each well, $100 \mu \mathrm{L}$ solution was transferred to 96 well plates then absorbance was determined at $590 \mathrm{~nm}$ using a the HTX microplate reader.

\section{Screening of antifungal activity}

The antifungal activity of the nanoparticles was tested against pathogenic yeasts as well as against various dermatophytes. The examined strains are listed in Table 1.

First, agar diffusion assay was carried out as described previously. ${ }^{20}$ Briefly, $5 \mu \mathrm{L}$ of the synthesized AuNP or AgNP suspensions $(5 \mathrm{mg} / \mathrm{mL})$ were loaded onto the surface of the plates seeded by the test strains. The plates were incubated at $30^{\circ} \mathrm{C}$ and the inhibition zones were determined after 24 hours.

Anti-dermatophyte activity was tested on potato dextrose agar (PDA; VWR, Radnor, PA, USA) plates. Agar plugs of $3 \mathrm{~mm}$ diameter were cut from 4-day-old cultures and inoculated upside down onto the surface of PDA plates supplemented with AgNP (in 10 or $30 \mu \mathrm{g} / \mathrm{mL}$ concentration) or with AuNP (first in 10 or $30 \mu \mathrm{g} / \mathrm{mL}$ and later in $300 \mu \mathrm{g} / \mathrm{mL}$ concentrations). Subsequently, the plates were incubated for 4 days at $30^{\circ} \mathrm{C}$ and the diameter of the colonies was measured.

All experiments were carried out at least three times using three biological replicates.

\section{Yeast viability assay}

The number of colony forming units (CFU) was determined to assess the viability of nanoparticle-treated $\mathrm{Cr}$. neoformans

Table I List of the tested strains

\begin{tabular}{ll}
\hline Species & Strain number \\
\hline Candida albicans & ATCC I023 I \\
Candida glabrata & CBS I38 \\
Candida krusei & CBS 573 \\
Candida parapsilosis & CBS 604 \\
Candida tropicalis & CBS 94 \\
Cryptococcus neoformans & IFM 5844 \\
Microsporum gypseum & SZMC II I 24 \\
Trichophyton mentagrophytes & SZMC II I 02 \\
Trichophyton tonsurans & SZMC II I 03 \\
\hline
\end{tabular}

Abbreviations: ATCC, American Type Culture Collection; CBS, Centraalbureau voor Schimmelcultures; IFM, Research Center for Pathogenic Fungi and Microbial Toxicoses, Chiba University; SZMC, Szeged Microbiology Collection. 
cells. Briefly, $4 \times 10^{6}$ yeast cells in Hanks' Balanced Salt solution (HBSS) were exposed to either AgNP or AuNP in concentrations of $1,5,10$, and $30 \mu \mathrm{g} / \mathrm{mL}$ for 24 hours at $30^{\circ} \mathrm{C}$. After treatment, cells were washed and were resuspended in $1 \mathrm{~mL}$ sterile water. A tenfold dilution series was prepared and $25 \mu \mathrm{L}$ aliquots from each dilution were spread onto YPD plates in triplicates. Non-treated cells were used as control. Plates were incubated at $30^{\circ} \mathrm{C}$ for 72 hours and the number of the colonies was counted. The experiments were carried out 3 times.

Following AgNP or AuNP treatments, the viability of $C r$. neoformans cells was examined by calcein-AM assay using flow cytometry. Briefly, $4 \times 10^{6}$ cells were exposed to 5,10 or $30 \mu \mathrm{g} / \mathrm{mL} \mathrm{AgNPs} \mathrm{or} \mathrm{to} 10$ and $30 \mu \mathrm{g} / \mathrm{mL}$ AuNPs in HBSS at $30^{\circ} \mathrm{C}$ for 24 hours. After the treatments, cells were washed with sterile distilled water, suspended in $200 \mu \mathrm{L}$ HBSS supplemented with $10 \mu \mathrm{g} / \mathrm{mL}$ verapamil (Sigma-Aldrich) and were incubated for $20 \mathrm{~min}$ at $30^{\circ} \mathrm{C}$ to block efflux transporter activity. Subsequently, calcein-AM (Thermo Fisher Scientific) was added in $10 \mu \mathrm{M}$ concentration and the suspensions were further incubated in the dark at $30^{\circ} \mathrm{C}$ for 3 hours. Cells were washed with HBSS and the fluorescent intensity was measured by flow cytometer (FlowSight $^{\circledR}$, Amnis-EMD Millipore) using a 488-nm excitation laser.

The time-dependent effect of nanoparticle treatments was investigated by exposing $4 \times 10^{6} \mathrm{Cr}$. neoformans cells in $1 \mathrm{~mL}$ HBSS to AgNP or AuNP in $10 \mu \mathrm{g} / \mathrm{mL}$ concentrations at $30^{\circ} \mathrm{C}$. After 1-, 3-, 10- and 24-hour treatments, aliquots of $100 \mu \mathrm{L}$ each were taken, and after a washing step were re-suspended in $1 \mathrm{~mL}$ sterile water. Then tenfold dilution series was prepared and from each dilution $25 \mu \mathrm{L}$ aliquots were spread onto the surface of YPD plates. Non-treated cells were used as control. The plates were incubated at $30^{\circ} \mathrm{C}$ for 72 hours and the number of the colonies was counted. The experiments were carried out three times, in three biological replicates.

\section{Results}

\section{Characterization of nanoparticles}

Particle morphology and size of the synthesized AgNPs and AuNPs were determined by TEM image analysis. According to the obtained TEM micrographs, AgNPs were quasi-spherical, well separated from each other and minor polydispersity could be observed (Figure 1A). The average size of the AgNPs proved to be $4.1 \pm 1.44 \mathrm{~nm}$. Gold particles were almost monodispersed, well separated and spherical with a narrow size distribution $(2.22 \pm 0.7 \mathrm{~nm})$. DLS measurements were also carried out to determine hydrodynamic particle sizes (Figure 1B). The average size of AgNPs was between 5 and $9 \mathrm{~nm}$ diameter, whereas the size of gold nanoparticles was around 4-7 nm. The formation of metal nanoparticles was ascertained by UV-VIS measurements (Figure 1C). The typical surface plasmon resonance (SPR) band of AgNPs appeared around 455 nm. UV-VIS spectra of AuNPs showed absorption peak maxima at $541 \mathrm{~nm}$ characteristic to SPR, which further supported the formation of metallic gold nanoparticles. In order to confirm the crystalline nature of the nanoparticles, XRD analysis was performed. The XRD pattern of the AgNP sample (Figure 1D) exhibited four identical diffraction peaks appearing at $2 \theta=38.4^{\circ}, 44.4^{\circ}, 64.7^{\circ}$ and $77.5^{\circ}$ corresponding to (111), (200), (220) and (311) planes of the face-centered cubic lattice structure of metallic silver ${ }^{21}$ (Joint Committee on Powder Diffraction Standards [JCPDS] No 87-0717). Crystallinity of the as-synthesized AuNPs was also investigated. Gold nanocrystals exhibited four distinct peaks at $2 \theta=39.4^{\circ}, 44.5^{\circ}, 65.7^{\circ}$ and $78.6^{\circ}$ corresponding to (111), (200), (220) and (310) Bragg's reflection based on the face-centered cubic structure of metallic gold (Figure 1D) (JCPDS No 4-0784).22

\section{Toxicity on human cells}

We assessed the cell viability of human skin-derived keratinocyte $\mathrm{HaCaT}$ cells treated with biologically synthesized AgNPs and AuNPs. MTT assays revealed that the nanoparticles, both AgNPs and AuNPs, applied in 0-60 $\mu \mathrm{g} / \mathrm{mL}$ concentrations, did not reduce the viability of $\mathrm{HaCaT}$ cells (Figure 2A). On the other hand, treatments with the wellknown therapeutic agent cisplatin caused considerable cytotoxicity, since significant loss of keratinocyte metabolic activity was observed already at $5 \mu \mathrm{g} / \mathrm{mL}$ cisplatin concentration (Figure 2A).

Cytotoxicity of AgNPs and AuNPs was analyzed by the crystal violet staining method (Figure 2B). AgNPs and AuNPs generated by $P$. rhodozyma cell-free extract were non-toxic to the applied human cells in the tested concentration range. Conversely, cisplatin proved to be significantly toxic to human $\mathrm{HaCaT}$ cells. These results indicate that these biogenic AgNPs and AuNPs exhibit no toxicity therefore both are biocompatible to human keratinocytes.

\section{Efficiency against pathogenic yeasts}

The antifungal activity of the prepared AgNPs and AuNPs was tested against various Candida and Cryptococcus species. AgNPs inhibited the growth of all the examined strains in agar diffusion assay except that of Candida tropicalis 
A

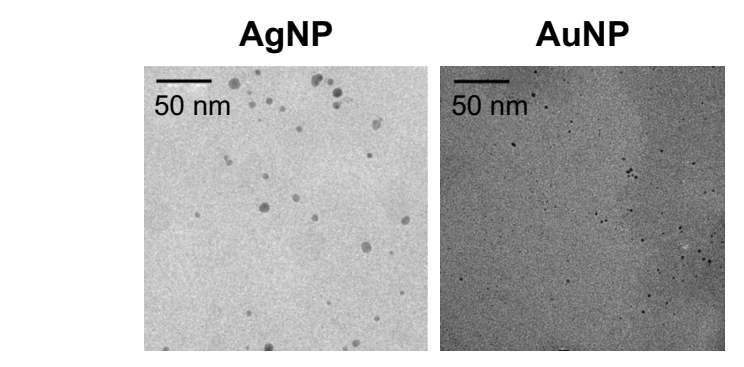

C
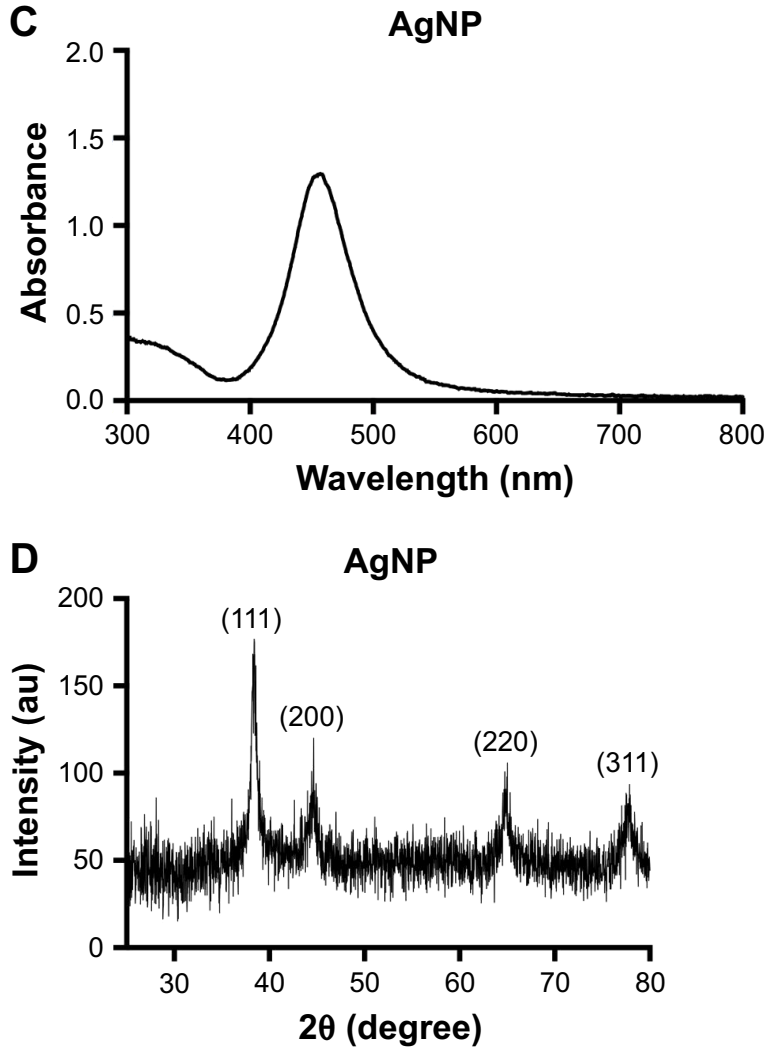

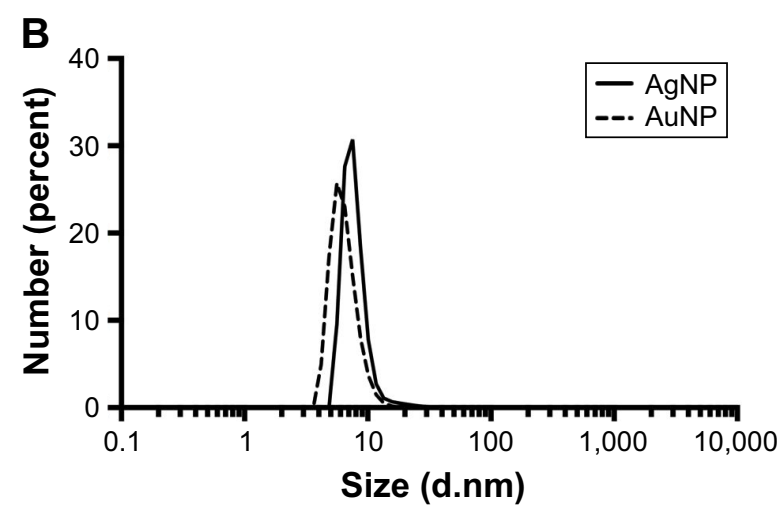

AuNP
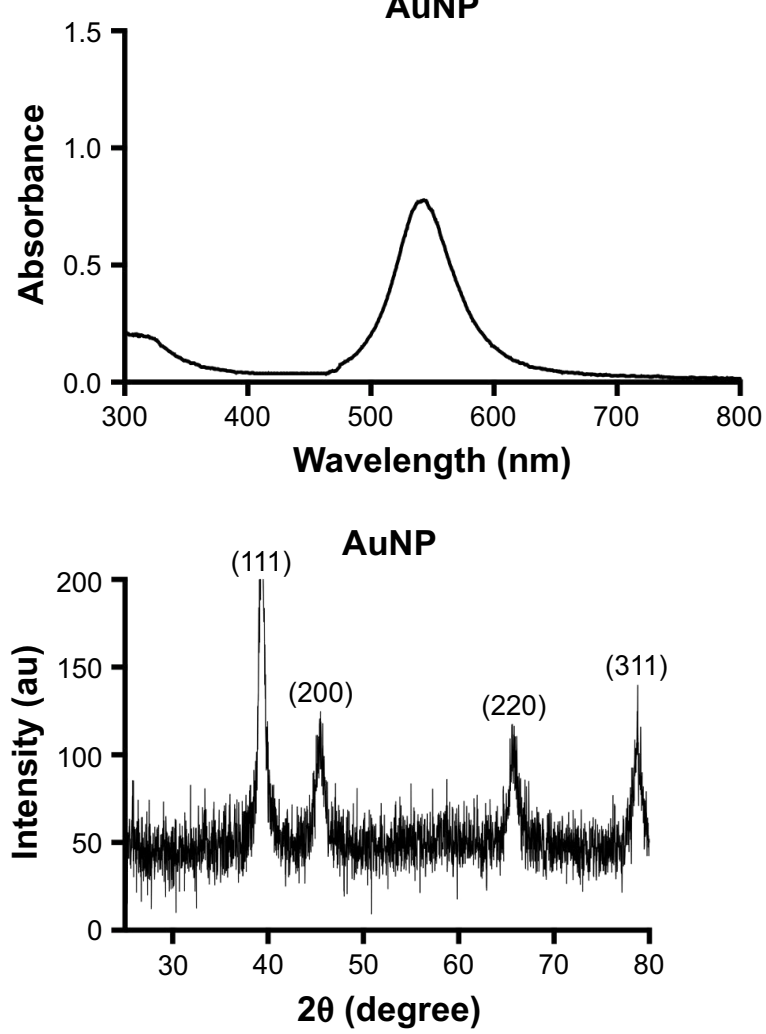

Figure I Physicochemical properties of AgNPs and AuNPs prepared by Phaffia rhodozyma cell-free extract. Transmission electron microscopic images of AgNPs and AuNPs (A), and size distribution of the nanoparticles by DLS measurements (B), UV-VIS spectra (C) and X-ray diffraction pattern (D).

Abbreviations: AgNP, silver nanoparticle; AuNP, gold nanoparticle; DLS, dynamic light scattering; UV-VIS, ultraviolet-visible.

(Figure 3A). Interestingly, Cr. neoformans was sensitive to AuNPs as well, whereas other species exhibited resistance against AuNPs (Figure 3A).

Since $\mathrm{Cr}$. neoformans appeared susceptible to both nanoparticles, the antifungal effect of AgNPs and AuNPs was assessed more quantitatively on this particular strain. Hence, $\mathrm{Cr}$. neoformans cells were subjected to different concentrations of AgNPs and AuNPs for 24 hours then cell viability was determined using colony forming assay (Figure 3B). Treatments with $1 \mu \mathrm{g} / \mathrm{mL}$ of either AgNPs or AuNPs already resulted in a significant loss of cell viability, whereas the number of viable $C r$. neoformans cells dropped below the detectable level following $30 \mu \mathrm{g} / \mathrm{mL}$ of AuNP or AgNP administrations (Figure 3B).

To further test the viability of nanoparticle-treated $\mathrm{Cr}$. neoformans cells, calcein-AM staining procedure was applied. As expected, increasing concentrations of either AgNPs or AuNPs gradually diminished the percentage of calcein-positive cells. After $10 \mu \mathrm{g} / \mathrm{mL}$ AgNP administration, approximately $50 \%$ of the cells were alive, while $83 \%$ of the examined cells were dead when AgNP concentration was elevated to $30 \mu \mathrm{g} / \mathrm{mL}$ (Figure 3C). A similar pattern was observed when yeast cells were exposed to AuNPs, since nanoparticle treatments in $30 \mu \mathrm{g} / \mathrm{mL}$ concentrations 


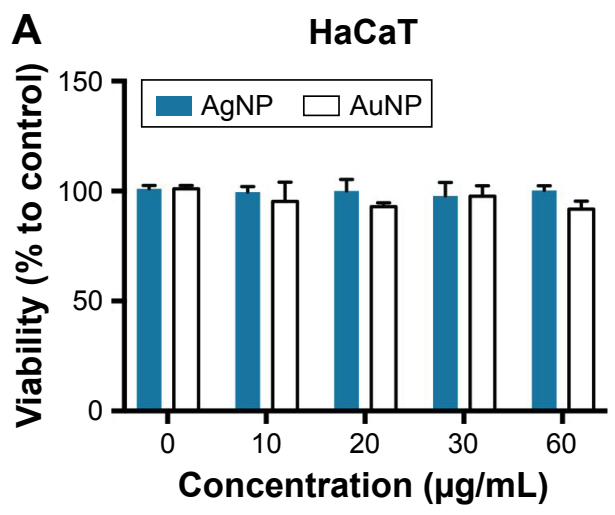

B

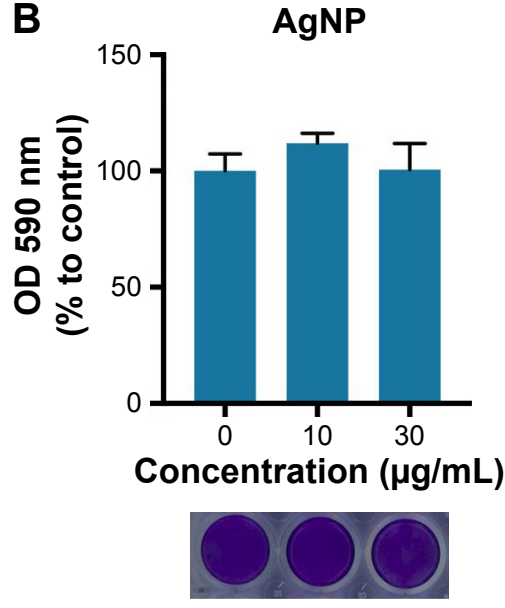

AuNP

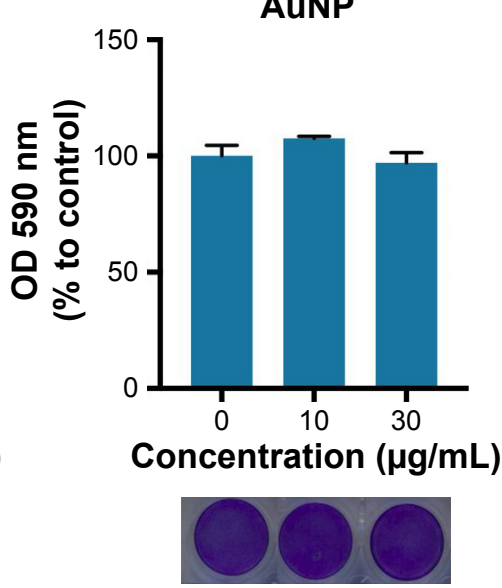

Cisplatin

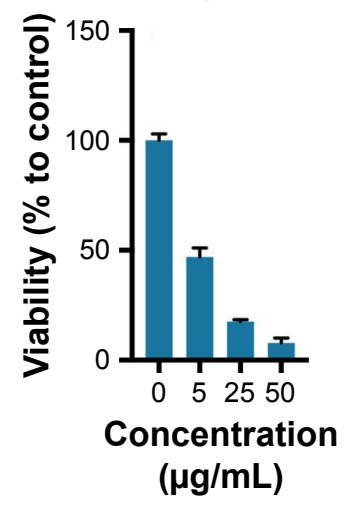

Figure 2 Cytotoxic effects of AgNPs and AuNPs on HaCaT human keratinocyte cells. Viability of the cells was detected by MTT assay after $24 \mathrm{~h}$ treatments of AgNPs or AuNPs (A). Cytotoxicity of AgNPs and AuNPs was determined by crystal violet staining; representative images of crystal violet stained cells are shown below column diagrams (B). Cisplatin was used as a positive control.

Abbreviations: AgNP, silver nanoparticle; AuNP, gold nanoparticle; OD, optical density.

decreased the percentage of the viable cells to approximately $50 \%$ (Figure 3C).

Time dependence of the nanoparticle-induced antifungal effect was also determined. For this purpose, Cr. neoformans cells were again subjected to $10 \mu \mathrm{g} / \mathrm{mL}$ AgNPs or AuNPs and after 1-, 3-, 10- and 24-hour treatments the number of the colonies was counted. Exposure to AgNPs for 1 hour caused a $50 \%$ decrease in the number of the CFU, but 10-hour treatments with either AgNPs or AuNPs reduced the number of viable cells below 10\% (Figure 3D).

\section{Anti-dermatophyte activity}

All the three examined dermatophyte species were sensitive to AgNP treatments in growth inhibition assay (Figure 4). AgNPs in $30 \mu \mathrm{g} / \mathrm{mL}$ concentration induced significant inhibition of colony growth, as the diameters of the colonies were markedly smaller, indicating an approximately $80 \%$ growth inhibition for each strain (Figure 4). On the other hand, none of the dermatophyte species reacted to AuNPs, when applied in 10 or $30 \mu \mathrm{g} / \mathrm{mL}$ concentrations. Therefore,
AuNP concentration was elevated up to $300 \mu \mathrm{g} / \mathrm{mL}$ but still no inhibition was detected (data not shown), indicating that AuNPs are not suitable for the growth inhibition of the examined cutaneous mycosis-causing dermatophyte fungi.

\section{Discussion}

Emerging problems associated with antibiotic-resistant microbes demanded new strategies to find novel antimicrobial agents. $^{23,24}$ Due to their broad spectrum activity, silver-containing materials have been used as antiseptics and disinfectants for decades, ${ }^{25}$ however the potential application of colloidal gold for medical purposes has only recently been recognized. ${ }^{26}$ Physical and chemical methods are generally considered as standard approaches for nanoparticle preparation, nevertheless these procedures lead to the accumulation of environmentally hazardous wastes. ${ }^{27}$ Furthermore, the presence of chemical residues within the nanoparticle colloid solutions limits their biomedical utilization. ${ }^{28}$ Biological synthesis is regarded as an eco-friendly and costeffective alternative for the production of biocompatible 

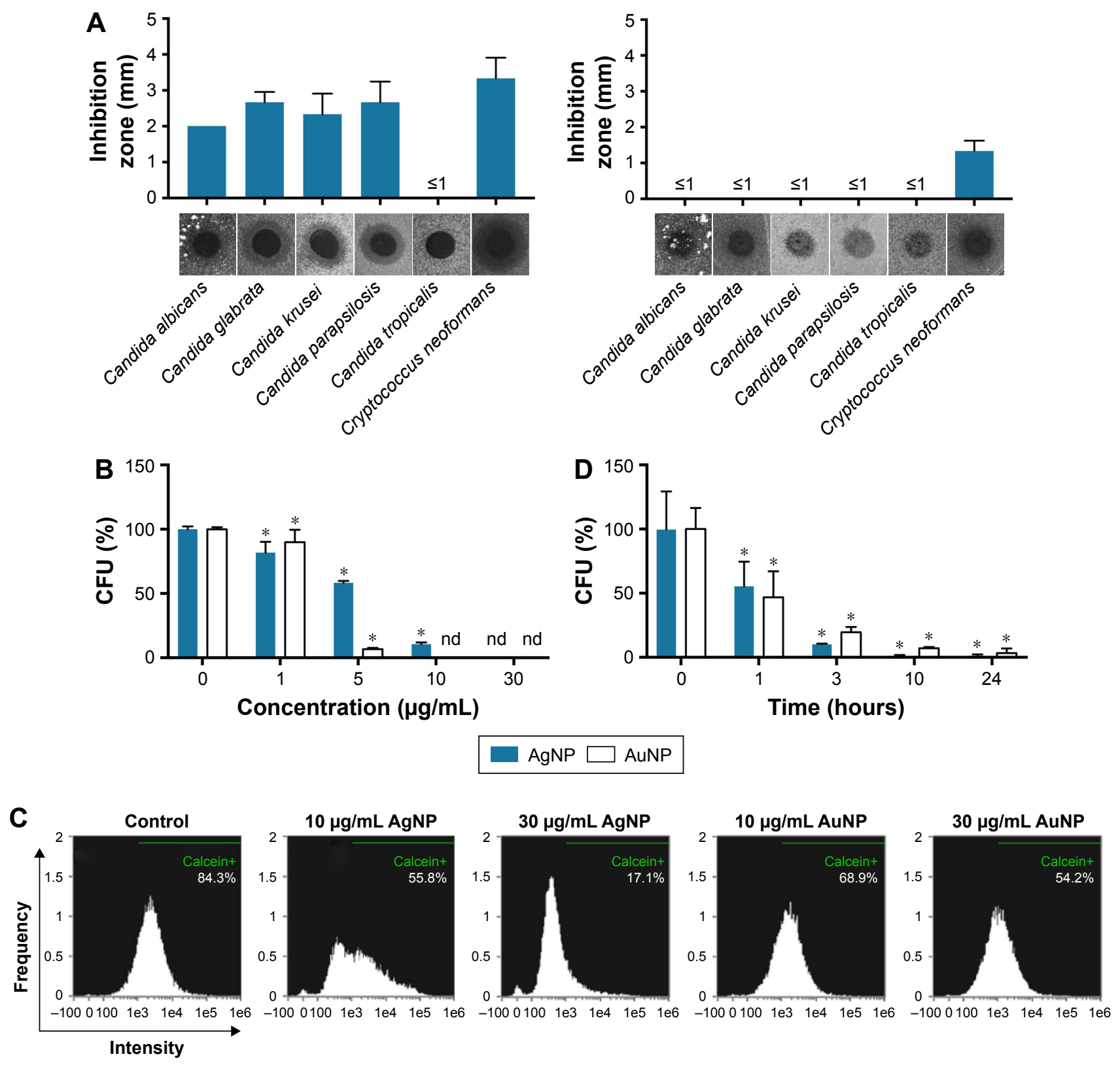

Figure 3 Antifungal activity of AgNPs and AuNPs, Agar diffusion assay and the size of the inhibition zones (A). Survival rate of Cryptococcus neoformans after AgNP or AuNP treatment determined by the establishment of the CFU (B) and flow cytometry (D). Time-dependent survival of $\mathrm{Cr}$. neoformans cells after exposure to $10 \mu \mathrm{g} / \mathrm{mL}$ AgNPs and AuNPs (C). *Two-way ANOVA $p \leq 0.05$.

Abbreviations: AgNP, silver nanoparticle; AuNP, gold nanoparticle; CFU, colony forming units; nd, non-detectable.

nanoparticles. ${ }^{29}$ The numerous publications reporting either living microorganisms, plants or cell-free extracts for the synthesis of nanomaterials highlight this rapidly expanding field of bionanotechnology. ${ }^{15,30}$

In this study, we investigated the suitability of P. rhodozyma cell-free extract for AuNP and AgNP preparation, since this microbe contains an effective antioxidant, astaxanthin in high concentration, which promotes the formation of metal nanoparticles. ${ }^{31}$ AgNPs and AuNPs were successfully synthesized and the biological activities of the as-prepared nanoparticles were subjected to complex analysis. AgNPs were effective against all the examined mycosis-causing fungal species, except for C. tropicalis. Most importantly, these biosynthesized silver particles were capable of inhibiting the growth of several opportunistic Candida or Cryptococcus species and were highly potent against filamentous Microsporum and Trichophyton dermatophytes. In addition, AgNPs were biocompatible, showing no cytotoxicity to human HaCat keratinocytes, which renders these biosynthesized AgNPs attractive candidates for further biomedical 


\section{A}

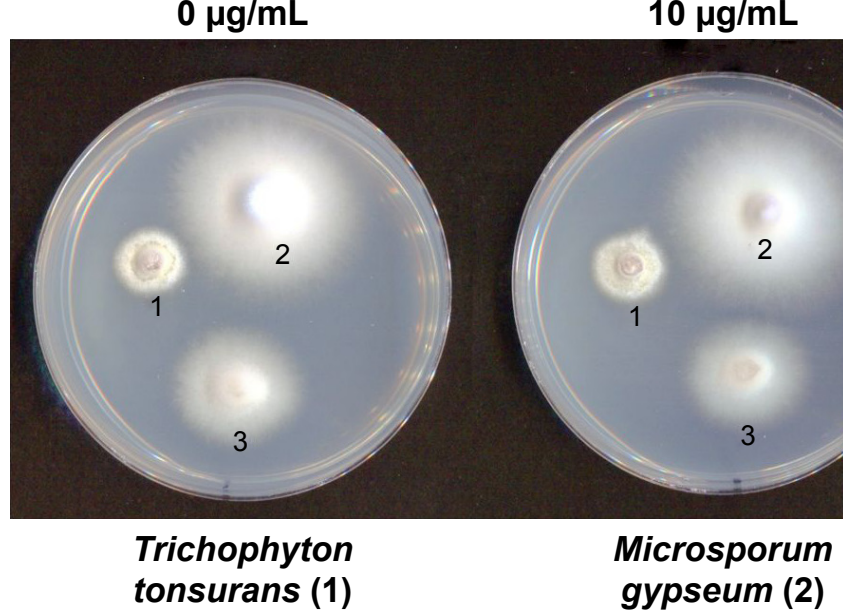

B
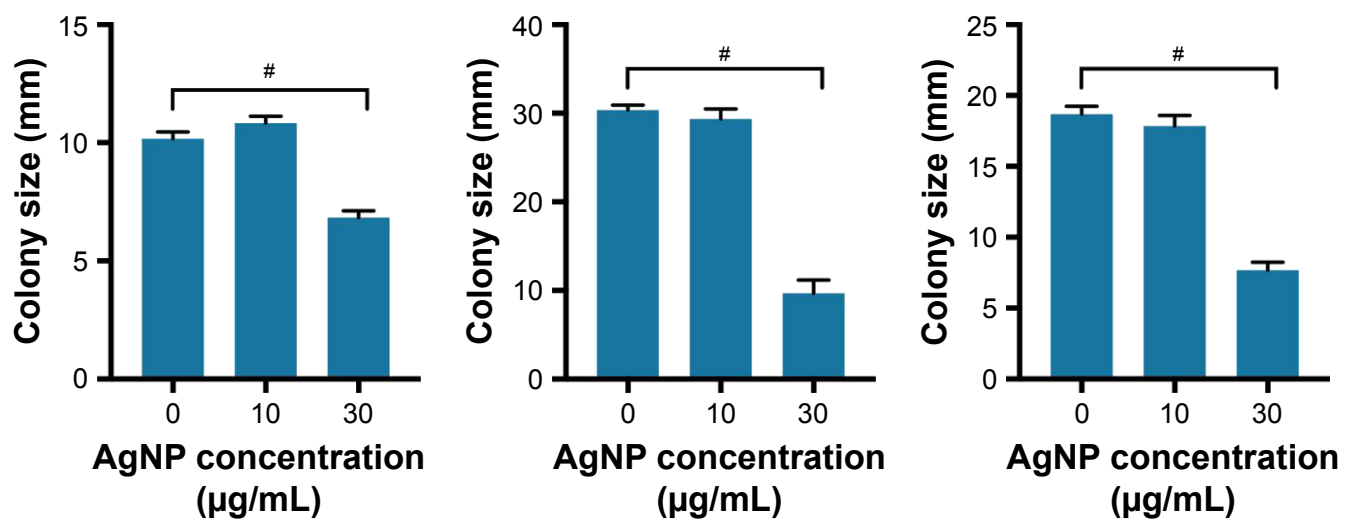

Figure 4 Anti-dermatophyte activity of silver nanoparticles. (A) Colonies of Trichophyton tonsurans (I), Microsporum gypseum (2) and Trichophyton mentagrophytes (3) on PDA and PDA supplemented with different concentrations of AgNP. (B) The bar charts represent the diameter of the colonies in the function of AgNP concentration. "Unpaired $t$-test $p \leq 0.05$.

Abbreviations: AgNP, silver nanoparticle; PDA, potato dextrose agar.

and pharmacological applications. It is also noteworthy that among the tested species only Cr. neoformans was susceptible to both AgNPs and AuNPs. We believe this is a relevant finding, since mainly antibacterial features of AuNPs have been demonstrated so far, ${ }^{32-34}$ while the scientific literature is short on investigations into the potential antifungal feature of AuNPs. ${ }^{35,36}$ Importantly, apart from their capacity to inhibit $C r$. neoformans, gold nanoparticles exerted no toxicity on human keratinocytes. These results emphasize the potential of such biosynthesized nanoparticles in topical dermatologic therapeutic strategies. Since cutaneous mycosis has the highest incidence among fungal infections, ${ }^{1,2,37}$ costeffective, novel treatment modalities should be introduced into the related clinical practice. The symptoms can range from subclinical (eg, itching, rash), to serious inflammatory reactions (eg, blistering, scarring, alopecia), requiring distinct treatment regimens. Furthermore, the infective species can induce severe complications in immunocompromised individuals, including organ transplant, hematology and oncology patients where the infected area can manifest ulceration or even tissue necrosis. ${ }^{3}$ The severity of these symptoms should be attenuated by complementary management using topical treatment approaches. We believe that biosynthesized metal nanoparticles could be implemented to improve the clinical outcome of cutaneous mycosis.

\section{Conclusion}

We found that the cell-free extract of $P$. rhodozyma is a suitable material for the synthesis of biogenic AgNPs and AuNPs. We demonstrated that these nanoparticles are potent against cutaneous mycosis-causing dermatophytes and opportunistic yeast species and are non-toxic to human keratinocytes. Considering our data in the context of the current clinical results, the biocompatibility to skin cells and the outstanding antifungal performance of our biosynthesized nanoparticles might be exploited during topical treatment of cutaneous mycosis or as a prophylactic treatment against the recurrence of the infection. 


\section{Acknowledgment}

This research was supported by the Hungarian Government and the European Union within the frames of the Széchenyi 2020 Programme through grant GINOP-2.3.2-15-2016-00035.

\section{Disclosure}

The authors report no conflicts of interest in this work.

\section{References}

1. Havlickova B, Czaika VA, Friedrich M. Epidemiological trends in skin mycoses worldwide. Mycoses. 2008;51(Suppl 4):2-15.

2. Thomas J, Jacobson GA, Narkowicz CK, Peterson GM, Burnet H, Sharpe C. Toenail onychomycosis: an important global disease burden. J Clin Pharm Ther. 2010;35(5):497-519.

3. Vander Straten MR, Hossain MA, Ghannoum MA. Cutaneous infections: dermatophytosis, onychomycosis, and tinea versicolor. Infect Dis Clin North Am. 2003;17(1):87-112.

4. Perfect JR, Casadevall A. Cryptococcosis. Infect Dis Clin North Am. 2002;16(4):837-874

5. Neuville S, Dromer F, Morin O, Dupont B, Ronin O, Lortholary O. Primary cutaneous cryptococcosis: a distinct clinical entity. Clin Infect Dis. 2003;36(3):337-347.

6. Tran QH, Nguyen VQ, Le AT. Silver nanoparticles: synthesis, properties, toxicology, applications and perspectives. Adv Nat Sci Nanosci Nanotechnol. 2013;4(3):033001.

7. Mohanpuria P, Rana NK, Yadav SK. Biosynthesis of nanoparticles: technological concepts and future applications. J Nanopart Res. 2008; 10(3):507-517.

8. Vimbela GV, Ngo SM, Fraze C, Yang L, Stout DA. Antibacterial properties and toxicity from metallic nanomaterials. Int J Nanomedicine. 2017;12:3941-3965.

9. Rao CN, Kulkarni GU, Thomas PJ, Edwards PP. Size-dependent chemistry: properties of nanocrystals. Chemistry. 2002;8(1):28-35.

10. Kovács D, Igaz N, Keskeny C, et al. Silver nanoparticles defeat p53positive and p53-negative osteosarcoma cells by triggering mitochondrial stress and apoptosis. Sci Rep. 2016;6:27902.

11. Kovács D, Szőke K, Igaz N, et al. Silver nanoparticles modulate ABC transporter activity and enhance chemotherapy in multidrug resistant cancer. Nanomedicine. 2016;12(3):601-610.

12. Ivask A, ElBadawy A, Kaweeteerawat C, et al. Toxicity mechanisms in Escherichia coli vary for silver nanoparticles and differ from ionic silver. ACS Nano. 2014;8(1):374-386.

13. Hebbalalu D, Lalley J, Nadagouda MN, Varma RS. Greener techniques for the synthesis of silver nanoparticles using plant extracts, enzymes, bacteria, biodegradable polymers, and microwaves. ACS Sustainable Chem Eng. 2013;1(7):703-712.

14. Ronavari A, Kovacs D, Igaz N, et al. Biological activity of greensynthesized silver nanoparticles depends on the applied natural extracts: a comprehensive study. Int J Nanomedicine. 2017;12:871-883.

15. Li X, Xu H, Chen Z-S, Chen G. Biosynthesis of nanoparticles by microorganisms and their applications. J Nanomaterials. 2011;2011: 270974.
16. Narayanan KB, Sakthivel N. Biological synthesis of metal nanoparticles by microbes. Adv Colloid Interface Sci. 2010;156(1-2):1-13.

17. Jha AK, Prasad K, Kulkarni AR. Yeast mediated synthesis of silver nanoparticles. Int J Nanosci Nanotechnol. 2008;4(1):17-22.

18. Ting Y, Teo W, Soh C. Gold uptake by Chlorella vulgaris. J Appl Phycol. 1995;7(1):97-100.

19. Johnson EA. Phaffia rhodozyma: colorful odyssey. Int Microbiol. 2003;6(3):169-174.

20. Ronavari A, Kovacs D, Vagvolgyi C, Konya Z, Kiricsi M, Pfeiffer I. Ion exchange defines the biological activity of titanate nanotubes. $J$ Basic Microbiol. 2016;56(5):557-565.

21. Sun Y, Xia Y. Shape-controlled synthesis of gold and silver nanoparticles. Science. 2002;298(5601):2176-2179.

22. Chen Y, Gu X, Nie C-G, Jiang Z-Y, Xie Z-X, Lin C-J. Shape controlled growth of gold nanoparticles by a solution synthesis. Chem Comm (Camb). 2005;(33):4181-4183.

23. Srinivasan A, Lopez-Ribot JL, Ramasubramanian AK. Overcoming antifungal resistance. Drug Discovery Today Technol. 2014;11:65-71.

24. Ghannoum MA, Rice LB. Antifungal agents: mode of action, mechanisms of resistance, and correlation of these mechanisms with bacterial resistance. Clin Microbiol Rev. 1999;12(4):501-517.

25. Edwards-Jones V. The benefits of silver in hygiene, personal care and healthcare. Lett Appl Microbiol. 2009;49(2):147-152.

26. Kon K, Rai M. The Microbiology of Skin, Soft Tissue, Bone and Joint Infections. Volume 2. Amsterdam: Elsevier Science; 2017.

27. Patra JK, Baek K-H. Green nanobiotechnology: factors affecting synthesis and characterization techniques. J Nanomaterials. 2014;2014:417305.

28. Parashar V, Parashar R, Sharma B, Pandey AC. Parthenium leaf extract mediated synthesis of silver nanoparticles: a novel approach towards weed utilization. Dig J Nanomater Biostruct. 2009;4(1):45-50.

29. Kharissova OV, Dias HVR, Kharisov BI, Pérez BO, Pérez VMJ. The greener synthesis of nanoparticles. Trends Biotechnol. 2013;31(4): 240-248.

30. Makarov VV, Love AJ, Sinitsyna OV, et al. "Green" nanotechnologies: synthesis of metal nanoparticles using plants. Acta Naturae. 2014;6(1):35-44.

31. Bharathiraja S, Manivasagan P, Quang Bui N, et al. Cytotoxic induction and photoacoustic imaging of breast cancer cells using astaxanthinreduced gold nanoparticles. Nanomaterials (Basel). 2016;6(4):E78.

32. Bindhu MR, Umadevi M. Antibacterial activities of green synthesized gold nanoparticles. Materials Lett. 2014;120:122-125.

33. Bindhu MR, Vijaya Rekha P, Umamaheswari T, Umadevi M. Antibacterial activities of Hibiscus cannabinus stem-assisted silver and gold nanoparticles. Materials Lett. 2014;131:194-197.

34. Lee KD, Nagajyothi PC, Sreekanth TVM, Park S. Eco-friendly synthesis of gold nanoparticles (AuNPs) using Inonotus obliquus and their antibacterial, antioxidant and cytotoxic activities. J Industr Eng Chem. 2015;26:67-72.

35. Yu Q, Li J, Zhang Y, Wang Y, Liu L, Li M. Inhibition of gold nanoparticles (AuNPs) on pathogenic biofilm formation and invasion to host cells. Scientific Rep. 2016;6:26667.

36. Chwalibog A, Sawosz E, Hotowy A, et al. Visualization of interaction between inorganic nanoparticles and bacteria or fungi. Int J Nanomedicine. 2010;5:1085-1095.

37. Vallabhaneni S, Mody RK, Walker T, Chiller T. The global burden of fungal diseases. Infect Dis Clin North Am. 2016;30(1):1-11.
International Journal of Nanomedicine

\section{Publish your work in this journal}

The International Journal of Nanomedicine is an international, peerreviewed journal focusing on the application of nanotechnology in diagnostics, therapeutics, and drug delivery systems throughou the biomedical field. This journal is indexed on PubMed Central, MedLine, CAS, SciSearch ${ }^{\circledR}$, Current Contents ${ }^{\circledR} /$ Clinical Medicine,

\section{Dovepress}

Journal Citation Reports/Science Edition, EMBase, Scopus and the Elsevier Bibliographic databases. The manuscript management system is completely online and includes a very quick and fair peer-review system, which is all easy to use. Visit http://www.dovepress.com/ testimonials.php to read real quotes from published authors. 